\title{
Measuring Higher Education Quality
}

Imagine a thickly overgrown garden where flowering plants are choked by rampant vegetation. The vision is one of confusion; order can be achieved only by sharp pruning. Highly mechanized equipment is available, but its indiscriminate use may create additional havoc. And, even if pruned judiciously, the results may not please equally all viewers.

This analogy was used effectively by institutional researchers at the 1980 AIR Forum in presenting perspectives about the crucial task of measuring higher education quality. Key ideas from the stimulating panel presentation about "Institutional Research Problems with Qualitative Dimensions" and the vigorous audience discussion are summarized here.

The garden represented higher education, which-having experienced rapid growth and decreasing elitism since the early 1950 's-now attempts to nurture a variety of students and institutional types. The struggling flowers, almost unnoticeable within the larger scene, are individual students striving for growth. Frequently, individual student progress is obscured by the use of group data presented to characterize higher education. The scene, as viewed by the public, lacks order and direction, as well as a clear focus on educational quality.

The move to assess educational quality serves two main goals: (1) to provide a way to examine the vision and dimensions of higher education in the 1980s; and (2) to improve credibility with the public. It is clear that these goals will not be accomplished satisfactorily if sophisticated statistical and computer tools are applied primarily to easily analyzed aspects of institutional functioning while larger issues of educational outcomes are ignored. Much effort is needed to redirect institutional research so that quality can be used as a basis for meaningful pruning rather than merely as a justification for reducing institutional budgets. Even if this massive task is under-

Panelists were: William Toombs, Pennsylvania State University; Patrick Terenzini, State University of New York at Albany; Lois Torrence, University of Connecticut. Joan Stark, University of Michigan, was moderator. 
taken, the constituencies holding higher education accountability may misinterpret the quality measures used unless adequate consensus about their interpretation is reached by academic leaders and adequately conveyed to the public.

\section{THE TIME FOR MEASURING QUALITY HAS COME}

The development of sophisticated statistical and management information systems has given institutional researchers considerable capability to describe the human, financial and physical resources of colleges and universities. But, although we are readily able to provide our publics with cost data, we are less skilled in describing educational value and outcomes. As financial strictures increase in the 1980s, it will become even more important to demonstrate the impact of higher education.

The cognitive growth of students has long served as the traditional basis for the support of higher education. However, the total growth of the student is probably a more effective focus for measuring quality. Underlying this assertion is the recognition that the effects of educational quality are lodged in the individual's total experience, which is shaped by all institutional elements, not simply those of a cognitive character. Clearly, all institutional factors influencing student development are worthy of examination. Indeed, if the impact of institutions and institutional processes upon people is not systematically examined, higher education runs the risk of underutilizing available technology, thus permitting data about space utilization, class size, and unit cost to replace clearly stated educational objectives as institutional goals. Unfortunately, it is not uncommon to find such data collected for their own sake, and consequently not correctly understood or used by decision makers.

Continued reliance upon statistical techniques without linking the quantitative measures to quality dimensions may also lead to overestimation of their predictive power. This is particularly true if decision making becomes more centralized at state and federal levels, where those far removed from the local campus may read such data as adequate descriptors of educational outcomes. Particularly dangerous is the misuse of so-called neutral quality formulas which homogenize institutional information so that variability among colleges is lost. Data used for decision making must be valid in terms of the individual college's educational objectives.

Not only must institutional researchers study the quality dimension of education; the impact of management information technology on institutional behavior also awaits examination. As in other aspects of society, technology advances adopted without assessment of their potential longterm impact may have unanticipated effects that become apparent only upon close examination or when a crisis is precipitated. 


\section{BUT THERE ARE SOME DIFFICULTIES}

All judgments about worth or quality are necessarily comparative. Comparisons may be (1) intuitive; (2) based on normative or standardized measures; or (3) based on specified criteria. Whatever the basis, comparative judgments must eventually rest on consensus about how the chosen standard will be applied. This consensus will be very difficult to achieve in a diverse higher education enterprise committed to expanded educational opportunity. While there is danger in establishing a single set of benchmarks that does not take into account the variability among higher education institutions and students, there is also danger that lack of standards may result in consistent mediocrity.

Another hazard in measuring educational quality is the differential interpretation of the measures used. For example, funders are accustomed to using cost in lieu of specified standards of accomplishment, while educators have other priorities. Data are collected to facilitate judgments but are not sufficient for improvement since they represent current conditions.

Consideration of quality issues will bring them to public notice, thus inviting challenges to earlier statements about institutional worth. We need to be prepared to treat both positive and negative responses from funding sources and other publics. The trade-off between potential lack of support because we lack credible quality measures and potential lack of support because we do provide poorly understood quality measures is not clear.

\section{ARE INSTITUTIONAL RESEARCHERS OBLIGED TO MEASURE QUALITY?}

The primary mission of institutional research is to ask the most significant questions to guide the collection and analysis of data. Others assign to us the mission of ensuring that information gathered is incorporated into various decision-making processes. Simply facilitating data collection without assessing the relative importance of questions posed and the manner in which the information will be used limits institutional research boundaries and reduces its potential influence.

Institutional researchers must maintain a balanced approach to the central issues of higher education. Currently, much attention is focused by researchers on process measures from which quality is inferred. Unfortunately, it appears that process measures, including the procedures for conducting institutional research, are becoming ends unworthy of the profession. Institutional researchers should encourage academic leaders to examine the full range of descriptors that provide a view of what the institution accomplishes. The achievement of quality, defined by consensus and clear institutional mission, should become the goal; the array of process and product measures should be linked to goal assessment. 


\section{ARE NEW TOOLS AND CONSTRUCTS NEEDED?}

One point of view is that quality is properly assessed across at least three levels or domains: (1) individuals, including students and staff; (2) departments, including academic and administrative units; and (3) institutions. At each level, design considerations for gathering evidence include such questions as: (a) What are the characteristics of the person, program, unit, or institution about which judgments of quality are to be made? In other words, what elements are judged to contribute to quality at each level? (b) What signifies the attainment of excellence for each element? Do these measures adequately assess the attainment of specified goals and objectives? (c) What is the standard or reference point to be used for comparison? and (d) What are the appropriate data collection and analytical procedures given the nature of the evidence?

A second view would hold that such a matrix, which juxtaposes the institutional domains against various design specifications now in common use, is reductionistic and inappropriate. Most of the measures implied within this matrix are unidimensional, whereas the concept of quality is multidimensional. Advocates of the multidimensional view point out that studies should focus on several variables simultaneously or on relationships among variables. For example, the relationship between student intellectual growth, faculty behavior, and the total curriculum would be seen as a more meaningful measure of quality than any of these measures taken separately and subsequently displayed together.

A third view, which carries the multidimensional view further, holds that the concept of quality is holistic. The ultimate measure is seen as the overall effect of the educational process on student growth and development. Quality is also seen as cumulative over time, implying that longitudinal rather than cross-sectional studies are the only valid technique to assess quality. Advocates of this position recognize that it is particularly hard to devise any uniform method for measuring the effect of education on individuals when (1) the population of students and the types of institutions are so varied; and (2) intellectual growth is not linear but varies in both rate and direction. The holistic approach calls for greater use of interview techniques, case studies, retrospective self-reports, existential analysis, and other qualitative methodologies focused primarily on assessing student growth but not totally ignoring the discernible effects of faculty and institutional settings on eventual outcomes.

\section{CONCLUSION}

The panelists indicated that considerable progress is being made by such organizations as ACT and NCHEMS in identifying the domains of quality 
to be measured and particularly in devising unidimensional indicators of student progress. Few were able to cite comparable advancements in the development of multivariate techniques to assess the relation of student growth to other variables. Notable progress in achieving consensus on appropriate standards for measuring quality institutions or curricular programs within comparable institutions remains as a future task.

Joan S. Stark and Malcolm A. Lowther The University of Michigan 